DOI 10.37882/2500-3682.2021.11.12

\title{
МЕТАФИЗИКА В ПАРАДИГМЕ СОВРЕМЕННОГО ФИЛОСОФСКОГО ДИСКУРСА
}

\section{METAPHYSICS IN THE PARADIGM OF MODERN PHILOSOPHICAL DISCOURSE}

\section{Savrey}

Summary: The rejection of modern culture from the primacy of the absolute, eternal, personal Principle, originally inherent in the metaphysical style of thinking, becomes a paradigmatic sign of our era with its total immersion in the sphere of material utopias realized, with its spiritual impoverishment and the death of disappearing traditions. If we talk about the awakening of a new metaphysical consciousness, then it is precisely to our time, when the contours of a total ideological and cultural crisis are becoming more and more noticeable on the horizon of the epoch, this awakening seems necessary. By blurring the boundaries of immanence, metaphysics opens up prospects for the destiny of humanity beyond time and world history.

Keywords: absolute beginning, being, eternity, time, worldview, culture, science, metaphysics, modernity, postmodernism, universe, philosophy, eschatology.

\author{
Саврей Валерий Яковлевич \\ Д.ф.н., профессор, МГУ им. М.В. Ломоносова \\ vsvry@icloud.com
}

Аннотация: Отказ современной культуры от примата абсолютного, вечного, личностного Начала, исконно присущего метафизическому стилю мышления, становится парадигмальным знаком нашей эпохи с её тотальным погружением в сферу осуществлённых материальных утопий, с её духовным оскудением и гибелью исчезающих традиций. Если говорить о пробуждении нового метафизического сознания, то именно нашему времени, когда на горизонте эпохи всё заметнее обозначаются контуры тотального мировоззренческого и культурного кризиса, это пробуждение представляется необходимым. Размыкая границы имманентности, метафизика открывает перспективы предназначения человечества за пределами времени и всемирной истории.

Ключевые слова: абсолютное начало, бытие, вечность, время, картина мира, культура, наука, метафизика, модерн, постмодернизм, универсум, философия, эсхатология.
$\Pi$ онятие «метафизика» с трудом укладывается в парадигму конкретных философских категорий, отражающих характер восприятия человеком картины мира в пространстве современной культуры. Метафизика перестала быть отправной точкой европейского сознания с его новым стилем мышления. Грандиозная философская система Гегеля стала мишенью для критики метафизики ещё в XIX в. B XX в. постмодернистская деконструкция с её критикой модерна, субъекта и системы приобрела чуждый умозрительной метафизической философской традиции рациональный характер. В. Панненберг в своём труде «Metaphysik und Gottesgedanke» объяснял критику метафизики влиянием Огюста Конта, рассматривавшего метафизику в качестве переходной ступени от мифологизма к позитивизму (Хаутепен А. Бог: открытый вопрос. М., 2008. С.75). Хайдеггер не без оснований считал, что период философского осмысления метафизической проблематики «завершён в своём существе» (Хайдеггер М. Время и бытие. М., 1993. С.148) , ввиду того очевидного факта, что интерпретация вопросов философии с позиций метафизики «бытийно - исторически пришла к концу» (Там же. С.148). На самом деле к концу пришло только лишь время, когда метафизика утверждалась «исключительно на априорном умозрении или на гениальных догадках, подсказанных поэтическим вдохновением» (Левицкий С.А. Трагедия свободы. М., 2008. С. 55). В Новое время ме- тафизика как раздел философии ставила задачу осмысления основ бытия в свете сформированной в процессе научного познания общей картины мира. Уход метафизики из области европейского гуманитарного знания, в котором она оставалась душой философии на протяжении более двух тысячелетий её сознательной истории, представляется принципиально невозможным. Ведь в оценке самого Хайдеггера, «в метафизике происходит осмысление существа сущего и выносится решение о существе истины» (Хайдеггер М. Время и бытие. М., 1993. С. 41). Жак Деррида, комментируя Аристотеля, говорит, что метафизика как первая философия является первой, потому что является общей, имеющей целью «рассмотреть сущее как сущее» (Деррида Ж. Поля философии. М., 2012. С. 215). В отличие от современного человека, который не может «выйти за пределы нашей системы мышления, герменевтического круга нашей позиции, «случайности» (Geworfenheit) нашего фактического существования» (Хаутепен А. Бог: открытый вопрос. М.,2008. С.75), первый человек в своей потенциальной возможности выхода в сферу трансцендентальных смыслов и ценностей мог мыслить в первую очередь категориями религиозного характера, то есть метафизически. На историческое первенство метафизики указывает тот факт, что в то время, когда в древней Греции все науки находились ещё в своей колыбели, «метафизика переживала эпоху величайшего в истории мировой мысли 
расцвета» (Левицкий С.А. Трагедия свободы. М., 2008. С.55). Стоявший у истоков отечественной философии, на пересечении восточно-христианских, возрожденческих и древнерусских традиций, сочетавший символический и научный методы осмысления бытия, занимавшийся разработкой проблем метафизики света, преподобный Максим Грек в своём письме Фёдору Карпову в 1524 г. дал определение философии как возвышенного божественного знания и ставил миссию философа выше царской (Громов М.Н. Максим Грек // Русская философия. Энциклопедия. М., 2020. С. 405), справедливо полагая, что своему высокому «царскому» статусу философия обязана прежде всего метафизике.

Если эпоха библейских пророков, классической античности и христианского средневековья вплоть до Нового времени была ознаменована присутствием в мировом универсуме высшего, абсолютного, трансцендентно-имманентного Начала, создающего ноуменальную основу бытия всего организованного порядка мироздания и направляющего мировой культурно-исторический процесс к конечной цели, находящейся за пределами исторического времени и включающей восстановление всего сущего во вневременных параметрах вечности, то на протяжении последних веков в историческом континууме цивилизационного процесса человек уже давно перестал думать и мыслить метафизически. Его мышление, будучи когда-то идеалистическим, теоцентричным, религиозно-догматическим, меняясь из века в век, становилось рациональным, эмпирическим, позитивистским, материалистическим, сциентистским, эволюционистским, скептическим, релятивистским, индифферентным, ризоматическим, номадологическим. Философские концепции, созданные в эпоху модерна в области метафизики, онтологии и логики, потеряли для современного человека свою прежнюю привлекательность и философскую значимость. «Конструируемые властным инстинктом разума вне исторические и вечные классические метафизические системы уступают место полифонии ризомы и доксы» (Воробьёва В.С. «Тотальность и бесконечное» // Постмодернизм. Новейший философский словарь. Минск, 2007. С.659). Отказ современной культуры от аксиологического акцента, присущего метафизическому стилю мышления, парадигмально обусловлен кризисом культуры современного мира и связанного с ним кризиса статуса философии как «царицы наук» в системе культуры (Можейко М.А. Метафизика // Постмодернизм. Энциклопедия. Минск, 2001. С.461). В своей временной погружённости в стихию имманентности современный человек стремится держаться на почтительной дистанции от сферы метафизических вопрошаний и поисков, тревожащих его уютное земное прозябание вечной и запредельной тайной. Однако принятие тайны, как заявляет Габриэль Марсель, есть в своей онтологической сущности «позитивный акт нашего ума» (Gabriel Marcel. Being and Having. New York: Harper and Row, 1965, p. 118). y
М. Хайдеггера этот акт интерпретируется как прозрение бытия в свете истины бытия, когда человек «бросает себя навстречу озарившему его свету, прочь от самого себя» (Хайдеггер М. Что такое метафизика? М., 2007. С.272), когда он становится способным отозваться «на обращённое к нему озарение» (Там же. С. 272) и в этой отзывчивости «взглянуть как смертный в лицо божественному» (Там же. С.272). Величие и онтологический статус человека подчинены мгновению, когда человек стремится «выйти за пределы всякого горизонта» (Ясперс К. Разум и экзистенция. М., 2014. С.183-184), находясь в условиях своей имманентной замкнутости, детерминированной пределами гносеологических возможностей. Лейбниц, Кант и Шеллинг могли ставить вопрос: почему существует Вселенная, а не Ничто. «Однако этот вопрос в своей рациональной бледности не даёт нам живо почувствовать ту ситуацию, в которой мы впервые по-настоящему переживаем бытие бытия как дарованное нам, непостижимое, непроницаемое, которое уже есть до всякого мышления и приближается к нам» (Там же. С.223-224). Хайдеггер с присущим ему философским дерзновением, как бы компенсирующим утраченный им религиозный опыт, заключает: «Иначе - никак; ибо и Бог, если он есть, остаётся Сущим, пребывает как Сущий в бытии и его сути, осуществляющейся в свете мира» (Хайдеггер М. Что такое метафизика? М., 2007. С.272).

Слово «метафизика» как термин и как понятие было введено в научный оборот александрийским библиотекарем Андроником Родосским, предложившим его в качестве названия трактата Аристотеля о «первых родах сущего» (Можейко М.А. Метафизика. Постмодернизм, Энциклопедия. Минск, 2001. С.461). По этому поводу Вильгельм Вундт в своей «Метафизике» заметил, что своим возникновением и названием метафизика обязана недоразумению: поскольку в системе Аристотеля она следовала «после физики», неоплатоники трансформировали это чисто внешнее название для обозначения той области философского знания, которая «выходит за пределы природы», и эта интерпретация удержалась по сегодняшний день (Вундт В. Метафизика// Философия в систематическом изложении. М., 2006. С.117). М. Хайдеггер в объяснении термина «метафизика» заключает: «Этот удивительный титул был позднее истолкован как обозначение такого исследования, которое выходит meta - trans - «за» сущее как таковое. Метафизика - это вопрошание сверх сущего, за его пределы» (Хайдеггер М. Время и бытие. М., 1993.С.24). Метафизика проливает свет в запредельную, ноуменально постигаемую область трансцендентального бытия. Первого европейского мыслителя, «первого настоящего метафизика, которого знает история, Гераклита, уже древние называли «Тёмным», указывая этим на глубокомысленную непонятность его изречений» (Вундт В. Метафизика// Философия в систематическом изложении. М., 2006. С.117). Если, по мысли А.Н.Уайтхеда, мы пожелаем воз- 
вести кого-либо в ранг величайшего метафизика, имея в виду гениальную интуицию и универсальный характер знаний, мы будем «должны отдать предпочтение Аристотелю» (Уайтхед А.Н. Избранные работы по философии. М., 1990. С. 235). В качестве важнейшего события в истории метафизики Уайтхед отмечает тот факт, что «Аристотель счёл необходимым завершить свою метафизику введением перводвигателя - Бога» (Там же. С. 235), благодаря чему его научно-философская система пробрела характер принципиальной фундаментальности, обусловленной присутствием в мировом универсуме абсолютного Начала, являющимся одновременно трансцендентальным и имманентным по отношению к сотворённому миру. В пророческом видении Исайи, когда Серафимы восклицали «Свят, Свят, Свят Господь Саваоф! Вся земля полна славы Его!» (Ис. 6,3), миру был явлен образ трансцендентно = имманентного Бога, поскольку этимологически слово «свят» (евр. «кадош») указывает на трансцендентность Бога, а слово «слава» - на Его имманентность. Образ трансцендентно-имманентного Бога присутствует в Откровении, теологии, классической онтологии и в метафизике.

Категории бытия сотворённых сущностей метафизика противопоставляет понятие «Ничто» как необходимую предпосылку, как Urgrund, как фон вселенской жизни (Inderweltsein), находящейся, согласно известному афоризму святителя Филарета Московского, под бездной благости Божьей, над бездной собственного ничтожества. В современной философии, весьма мало склонной к онтологической проблематике, идея Ничто «выявлена лучше всего в экзистенциальной философии Хайдеггера» (Левицкий С.А. Трагедия личности. М. 2008. С.159).

Метафизика обладает исключительной привилегией вступать в область запредельного и трансцендентного универсума с опорой на присущую человеку способность интуитивного проникновения в сферу сокровенных смыслов и ценностей, вполне резистентных к методу их рационального объяснения с позиций эмпирической науки и неклассической философии. В качестве примера можно указать на попытки интерпретации с позиций современной физики библейского тезиса о творении мира в творческом божественном акте из ничего (ex nihilo). Как отмечает один из современных исследователей, «любая физическая концепция «начального состояния» Вселенной - сингулярность, возбуждённый вакуум, суперструны или даже чисто абстрактная математическая идея - модель - не есть в полном смысле «ничто», так как данные состояния бытия в той или иной степени характеризуются определёнными параметрами» (Мумриков Олег, иерей. Концепции современного естествознания. Сергиев Посад, 2014. С.242). Абсолютное «ничто» - это такое ничто, о котором решительно ничего нельзя сказать, и для самого приблизительного представления, о котором даже абсолютный холод (- 273 градуса) или абсолют- ный мрак (абсолютно чёрное тело) могут служить лишь отвлечённым подобием. С точки зрения метафизики, «ничто» представляет собой антипод бытия, оно диалектически противостоит реальности бытия. В непобеждённой стихии косности и инертности твари истоки «ничто» проявляют себя в феноменологии физических аномалий и биологической смерти, имеющих место в существовании Вселенной. Видимый космос не является в абсолютном и идеальном смысле порядком и красотой, заслуживающих наименования «космоса», поскольку грехом человека в состояние Вселенной внесены дисгармония и разлад. По замечанию В.Н. Лосского, «порядок, в котором есть место для смерти, остаётся порядком катастрофическим» (Лоссий В.Н. Очерки мистического богословия. Догматическое богословие. М., 1991. С.253).

В своей теологической версии метафизика предусматривает наступление финального метаморфоза созданной Вселенной: физическая природа Вселенной полна неожиданностей, и материя оказывается гораздо более таинственной, чем считалось на протяжении предшествующих веков, что открывает возможность экстраполяции современных научных трактовок на будущее состояние нашего физического мира. Если каждая человеческая личность и всё человечество в своей совокупности представляют в метафизическом аспекте ипостась всего космоса, то под «метаморфозой» следует понимать преодоление человеком своего состояния падения, унаследованного человечеством от Адама, и сообразование его существования «с образом нового человека, Христа» (Бонхёффер Д. Этика. М., 2013. С. 334335). Событие Преображения Христа признаётся в догматическом учении Церкви метафизическим основанием будущего преображения мира в грядущем событии всеобщего воскресения всех умерших. Участие человека в божественной жизни во Христе необходимо должно вести к распространению этого нового строя преображённой жизни на всё творение в направлении противостояния всеобщему распаду (Колинз Р. Божественное действие и эволюция // Оксфордское руководство по философской теологии. М., 2013. С.379).

Современная научная картина мира, как и классическая немецкая философия, ставит перед философией большой метафизический вопрос: почему существует мир, представляющий собой грандиозную и необъятную Вселенную, и почему в этой Вселенной присутствует человек как носитель разумного и творческого волевого начала, в то время как с точки зрения фундаментальной науки с далеко превосходящей долей вероятности (порядка десяти в 144 степени) могло бы быть только одно «ничто»? Несомненно, этот вопрос таит в себе глубинное вопрошание о бытии, будучи рождён беспредельным метафизическим удивлением, свойственным величайшим гениям человечества от Аристотеля и Плотина до Мартина Хайдеггера и Карла Ясперса. «Даже если мы по- 
нимаем в себе всё, что может быть концептуально схвачено, мы всё же могли бы удивляться, изумляться или поражаться своим бытием» (Уэйнрайт У. Дж. Теология и тайна // Оксфордское руководство по философской теологии. М., 2013.С. 159). В современном мире и наука, и философия, и история способны актуализировать этот фундаментальный, бытийный, ценностно-смысловой вопрос, так что принципиально любой мыслящий человек, причастный к сфере интеллектуальной и мировоззренческой культуры, вслед за Николаем Гартманом, не может не считать, что если бывает какое-либо пробуждение метафизического и ценностного сознания, то «именно нашему времени оно необходимо» (Гартман Н. Этика. СПб., 2002. С.99).

В метафизической картине мира «ничто» преодолевается в акте божественного творения, в исторических событиях, ознаменованных Божественным воплощением и Воскресением. В исторической миссии христианства человечеству задана программа актуального усвоения спасительных плодов победы Христа над смертью и распространения следствий этой победы на всё человечество и на весь мир. Воскресение Христа, Бога и Человека, стало необходимой предпосылкой наступления Царства Божьего. В свете божественного предназначения мировой исторический процесс, осуществляемый под знаком синергии человеческого и божественного начал, имеет своей конечной целью финальный метаморфозис мира, то есть его окончательное преображение энергиями (действиями) божественной благодати. Эсхатологическое будущее воспринимается как проект, внесённый в жизнь мира христианством две тысячи лет назад. Этот проект подлежит оценке как аргумент, аксиоматическое достоинство которого удостоверяется внутренним свидетельством религиозного и мировоззренческого сознания принципиально каждого человека. Других более оптимистических перспектив в плане конечного преодоления присутствующего в бытии мира и в парадигме человеческой экзистенции энтропийного начала во всей истории человеческой цивилизации никем не предлагалось, и было предложено в единственный момент истории только Тем, Кто после своего Воскресения в минуту манифестации своего абсолютного онтологического первенства имел основания сказать: «Дана Мне всякая власть на небе и на земле» (Мф. 28, 18). В своих фундаментальных метафизических построениях христианская философская традиция исходит из истин Откровения, поскольку вне Откровения человеческий разум обречён на неизбежный релятивизм. Весьма симптоматичным является замечание Хайдеггера: «В философии, тем более в метафизике, всё шатко» (Хайдеггер М. Время и бытие. М.,1993. С.327). Вне веры в Откровение метафизика не способна иметь ни абсолютных гарантий, ни оптимистических перспектив. Николай Гартман, который стал последним немецким философом, создавшим целостную философскую систему, философ - клас- сик, критическая онтология которого в своей философской парадигме далека от фундаментальной онтологии Хайдеггера, очень верно заметил, что современного человека «уже ничто не возвышает, не трогает, не увлекает до глубины души» (Гартман Н. Этика. СПб., 2002.С.99). Свою инертность и косность, «свою неспособность к удивлению, изумлению, восторгу, благоговению он превращает в устойчивую, предпочтительную жизненную форму» (Там же. С.99), навеянную мнимой в своём иррациональном пессимизме интуицией текучести, ущербности, необратимости и невосполнимости бытия. «В конечном счёте у него на всё остаётся лишь ироническая или усталая усмешка» (Там же. С.99). В персоналистической философии Жана Лакруа, стремившегося, как и Франц Баадер, и Пауль Тиллих, постичь вечность как «вечное настоящее», человеку дана исключительная привилегия через время «достичь вечности» (Гайденко П.П. Время. Длительность. Вечность. М., 2007.С. 424). Тема метафизики времени и вечности нашла отражение в философии С.А. Левицкого, для которого «Боговоплощение есть свободное вхождение вечности во время, что является залогом ответного свободного вхождения времени в вечность - залогом воскресения времени в преображённом, целостном его прообразе» (Левицкий С.А. Трагедия свободы. М., 2008. С.138 -139). Как истина высшего метафизического порядка это свидетельство Откровения предполагает способность к глубокому погружению в созерцание. «Жизнь сегодняшнего человека не способствует углублению. Она лишена покоя и созерцательности» (Гартман Н. Этика. СПб., 2002. С. 99). Современному человеку недоступен опыт переживания теофаний и ангелофаний, который был присущ людям патриархальной эпохи. Попытки Леви Брюля в критике Тейлора и Фрезера открыть картину мышления первобытного человека свидетельствуют о том, что «мышление первобытное принадлежит к более высокому типу, чем мышление человека XIX в., ибо выражает мистическую близость познающего к своему предмету» (Бердяев Н.А. О назначении человека. М., 1993. С.88). В реконструкции образа мышления первобытного человека, являющимся мышлением глубинным в его функциональной предметности и более прозрачным в его бытийной укоренённости, необходимо учитывать присутствие эмоционального фактора, инспирированного не атрофированным рациональным сознанием благоговейного чувства, которое А. Швейцер называл благоговением перед жизнью. Это чувство «всесторонне и глубоко пронизывает всякое впечатление, размышление и решение человека» (Швейцер А. Благоговение перед жизнью. М., 1992. С. 222). С точки зрения А. Швейцера, рациональное мышление, следуя логической последовательности, приходит к парадоксальной необходимости признания сверхрационального метафизического базиса, отсутствие которого ведёт к образованию «безжизненных, лишённых какой-либо ценности» (Там же. С.89) мировоззренческих установок. 
В оценке Жака Деррида, в европейской философии XX в. существенным образом сохраняется «метафизическое единство человека и Бога, отношение человека к Богу, проект становления Богом как проект, задающий человеческую реальность» (Деррида Ж. Поля философии. М., 2012. С. 144). При этом, как заявляет Деррида, «атеизм ничего не меняет в этой структуре» (Там же. С. 145). Когда П.Сартр, описывая структуру человеческой реальности, называет свою философию «феноменологической онтологией», он создаёт философскую антропологию, в которой остаётся неразрывным «метафизическое родство с тем, что столь естественно соотносит «нас» в речи философа с «нами - людьми», с «нами» в горизонте человечества» (Там же. С.144). В конце своей книги «Бытие и ничто» Сартр ставит программным вопросом вопрос единства бытия как тотального сущего, он придаёт этому вопросу глубинно значимый титул «метафизический», утверждая принцип метафизического единства бытия (Там же. С. 145). Единство тотальности сущего связывается в человеческой реальности с осознанием человеком самого себя: «человек теряет себя в качестве человека, чтобы родился Бог» (Sartre J. $P$. $L$, etre et le neant. Esse d,ontologie phenomenologique. Paris, 1947. Р. 707). В интерпретации Сартра «это синтетическое единство определяется как нехватка - нехватка тотальности сущего, нехватка Бога, которую всегда торопливо превращали в нехватку в Боге» (Ibid. P. 714). Сартр заключает: «Человеческая реальность - это недостающий Бог» (lbid. P. 714). Как отмечает Ж.Деррида, «пример сартровской попытки замечательным образом подтверждает тезис Хайдеггера, согласно которому «любой гуманизм остаётся метафизическим», поскольку метафизика является другим именем онто-теологии» (Деррида Ж. Поля философии. М., 2012. С.145). Философия Сартра, связанная своими корнями с феноменологией Гуссерля и экзистенциальной онтологией Хайдеггера, в которой «человек задет в своём существе молнией бытия» (Хайдеггер М. Что такое метафизика? М., 2007. ( 272), создаёт в философской парадигме XX в. типологическую модель той «метафизики», которая воспринимается как путь философской интерпретации человеческого существования. По мысли В.Вунда, никакие отдельные области человеческого знания не способны выполнить ту задачу, которая возложена на метафизику, интегрирующую весь познавательный опыт человечества «в единое мировоззрение» и ярче всех других явлений отражающую «духовный характер времён» (Вунд В. Метафизика // Философия в систематическом изложении. М., 2006. С. 148). Выполняя своё исконно присущее ей предназначение, метафизика по - прежнему сохраняет своё присутствие в философском дискурсе нашей эпохи.

\section{ЛИТЕРАТУРА}

1. Бердяев Н.А. 0 назначении человека. М., 1993.

2. Бонхёффер Д. Этика. М., 2013.

3. Воробьёва В.С. Тотальность и бесконечное // Постмодернизм. Новейший философский словарь. Минск, 2007.

4. Вунд В. Метафизика // Философия в систематическом изложении. М., 2006.

5. Гайденко П.П. Время. Длительность. Вечность. М., 2007.

6. Гартман Н. Этика. СПб., 2002.

7. Громов М.Н. Максим Грек // Русская философия. Энциклопедия. М., 2020.

8. Деррида Ж. Поля философии. М., 2012.

9. Коллинз Р. Божественное действие и эволюция // Оксфордское руководство по философской теологии. М., 2013.

10. Левицкий С.А. Трагедия свободы. М., 2008.

11. Лосский В.Н. Очерки мистического богословия. Догматическое богословие. М., 1991.

12. Можейко М.А. Метафизика //Постмодернизм. Энциклопедия. Минск, 2001.

13. Мумриков Олег, иерей. Концепциисовременного естествознания. Сергиев Посад, 2014.

14. Уайтхед А.Н. Избранные работы по философии. М., 1990.

15. Уэйнрайт У. Дж. Теология и тайна //Оксфордское руководство по философской теологии. М., 2013.

16. Хайдеггер М. Что такое метафизика? М., 2007.

17. Хаутепен А. Богб открытый вопрос. 2008.

18. Швейцер А. Благоговение перед жизнью. М., 1992.

19. Ясперс К. Разум и экзистенция. М., 2014.

20. Marcel G. Being and Having. New York: Harper and Row, 1965.

21. Sartre J.P. L, etre et le neant. Esse d,ontology phenomenoloique. Paris, 1947.

22. Pannenberg W. Metaphysik und Gottesgedanke. Gottingen, 1988.

(с) Саврей Валерий Яковлевич (vsvry@icloud.com). 